\title{
Left Inferior Frontal Convolution
}

National Cancer Institute

\section{Source}

National Cancer Institute. Left Inferior Frontal Convolution. NCI Thesaurus. Code C32962.

A gyrus on the outer surface of the left frontal lobe of the cerebrum located between the inferior frontal sulcus and the fissure of Sylvius that is involved in response inhibition. 